\title{
Article
}

\section{Kinetics of Hydrolytic Depolymerization of Melt Poly(ethylene terephthalate)}

Chih-Yu Kao, Ben-Zu Wan, and Wu-Hsun Cheng

Ind. Eng. Chem. Res., 1998, 37 (4), 1228-1234 • DOI: 10.1021/ie970543q

Downloaded from http://pubs.acs.org on November 26, 2008

\section{More About This Article}

Additional resources and features associated with this article are available within the HTML version:

- $\quad$ Supporting Information

- $\quad$ Links to the 4 articles that cite this article, as of the time of this article download

- $\quad$ Access to high resolution figures

- $\quad$ Links to articles and content related to this article

- $\quad$ Copyright permission to reproduce figures and/or text from this article

\section{View the Full Text HTML}

\section{ACS Publications}




\title{
Kinetics of Hydrolytic Depolymerization of Melt Poly(ethylene terephthalate)
}

\author{
Chih-Yu Kao, ${ }^{\dagger}$ Ben-Zu Wan, ${ }^{*, \dagger}$ and Wu-Hsun Cheng ${ }^{\dagger}$ \\ Department of Chemical Engineering, National Taiwan University, Taipei, Taiwan, Republic of China, and \\ Department of Chemical Engineering, Chang Gung College of Medicine and Technol ogy, Kweishan, Taoyuan, \\ Taiwan, Republic of China
}

\begin{abstract}
The hydrolytic depolymerization of poly(ethylene terephthalate) (PET) was carried out in a stirred batch reactor at 235,250 , and $265^{\circ} \mathrm{C}$ above its melting point and under autogenous pressure. The solid products which were mainly composed of terephthalic acid were analyzed by potentiometric titration and elemental analysis. The liquid products which were mainly composed of ethylene glycol and a small amount of its dimer were analyzed by gas chromatrography. A kinetic model consisting of forward and backward reactions for the PET hydrolysis fitted well with the experimental data. Moreover, an autocatalytic mechanism was suggested, which indicates that some of the hydrolytic depolymerization of PET was catalyzed by the carboxyl groups produced during the reaction. The dependence of the rate constant on the reaction temperature was correlated by the Arrhenius plot giving the activation energy of 123 $\mathrm{kJ} / \mathrm{mol}$ for the PET hydrolysis.
\end{abstract}

\section{Introduction}

The recycling amount of poly(ethyl ene terephthalate) (PET) from packaging containers is rising yearly (Nir et al., 1993), and thus the reuse of PET waste draws much industrial interests (Paszun and Spychaj, 1997). The PET waste can be melted and then reformed into different articles; however, the products possess inferior properties and is limited to the application for nonfood purposes (Nir et al., 1993). In contrast, the hydrolytic depolymerizing PET waste into the original feedstocks (i.e., terephthalic acid and ethylene glycol) from which the virgin resins are regenerated shows potentially commerical benefits (Culp, 1994).

Although the process for the hydrolytic depolymerization of PET at high temperatures has been revealed in a number of patents (Mandoki, 1986; Rosen, 1992; West, 1995), the studies on the reaction kinetics for the process have been few. Several research studies were conducted on the reaction kinetics for the hydrolytic depolymerization of PET at low temperatures (i.e., less than $200{ }^{\circ} \mathrm{C}$ ) (Golike and Lasoski, 1960; Ravens and Ward, 1961; Zimmerman and Kim, 1980; Ballara and Verdu, 1989; Sao and Cloyd, 1991; Launay et al., 1994). However, the effort of those authors was mainly focused on measuring the degradable properties of the material so that the conversions of PET hydrolysis were rather low $(<1 \%)$ and were not applicable to the practical depolymerization process. The kinetic studies of PET hydrolysis at high conversions were recently reported by Campanelli et al. (1993). These authors proposed an analytical method for the whole range of conversions, by which the rate constants of PET hydrolysis were obtained from the initial rate data. However, they observed a low activation energy $(56 \mathrm{~kJ} / \mathrm{mol})$, which was inconsistent with activation energies (90-120 kJ /mol)

\footnotetext{
* To whom correspondence should be addressed.

† National Taiwan University. Fax: (+866-2) 23623040.

₹ Chang Gung College of Medicine and Technology. Fax: $(+866-3) 3283031$.
}

for PET hydrolysis found in the early studies (Golike and Lasoski, 1960; Ravens and Ward, 1961). Furthermore, the kinetics of PET hydrolysis catalyzed by zinc compounds was also investigated in their later work (Campanelli et al., 1994). The catalytic effect was found to be insignificant. These results imply that a significant mass-transfer resistance may exist in their reaction system, so that low activation energy and insignificance of catalytic effect were observed. Ther efore, the intrinsic reaction kinetics for hydrolytic depolymerization of $\mathrm{PET}$ may have not been clear yet.

To further investigate the hydrolytic depolymerization of PET, we have carried out a series of experiments under controlled reaction conditions to avoid masstransfer resistance. In this paper, the hydrolysis of PET was studied at the temperatures above its melting point using a pressurized reactor. The reaction kinetics was investigated, and the plausible mechanisms were discussed. Furthermore, the effects of the type of PET resins on the hydrolytic depolymerization were explored.

\section{Experimental Section}

PET resins used in this study were commerical fresh chips of fiber grade with dimensions of $3.5 \mathrm{~mm}$ in its diameter and length. The intrinsic viscosity (IV) of PET was measured in a 6:4 (w/w) phenol/1,1,2,2-tetrachloroethane solution at $30{ }^{\circ} \mathrm{C}$. The average molecular weight ( $M$ ) was calculated from the equation of $M=3.61$ $\times 10^{4} \mathrm{IV}^{1.46}$ (Kamatani et al., 1980). The melting of the resins is about in the temperature range of 235-265 ${ }^{\circ} \mathrm{C}$, as determined by a differential scanning calorimetry (DSC) at a heating rate of $10^{\circ} \mathrm{C} / \mathrm{min}$. Actually, when the PET resins with an excess amount of water were heated in a pressurized reactor, an apparent endothermic phenomenon of the resins due to its melting occurred at about $220^{\circ} \mathrm{C}$, while a hysteresis of melting temperature was observed. Moreover, after heating to $220^{\circ} \mathrm{C}$ and cooling to room temperature, the chips were found to be in a block state. This shows that the PET chips can melt at $220{ }^{\circ} \mathrm{C}$ in the presence of water 
under pressure. In this work, the hydrolysis of PET melts was therefore conducted above the temperatures of $220^{\circ} \mathrm{C}$ in a pressurized reactor. Deionized water was used as the reactant for the hydrolytic reaction.

The experiments of PET hydrolysis were carried out in a Parr 4560 mini reactor equipped with a bomb of $300 \mathrm{~mL}$ and a variable speed motor for stirring. PET chips and water were charged into the reactor at room temperature and then heated directly to the temperatures specified for conducting hydrolytic reactions. After the required time interval for hydrolytic reaction was reached, the vessel was quickly removed from the heating mantle, immersed in an ice bath, and quenched to ambient conditions. Then the mixture from the bomb was separated by a sintered glass filter to obtain the solid phase and the liquid phase. The liquid phase, mainly composed of water, ethylene glycol, and diethylene glycol, was directly used for analysis. The solid phase, mainly composed of unreacted PET, oligomers, and terephthalic acid, was further washed by deionized water, dried at $80{ }^{\circ} \mathrm{C}$, and ground until a fine powder was obtained.

The procedures of titration for the carboxylic acid concentration in hydrolyzed solid products followed those adopted by Campanelli et al. (1993). Two solvent systems, dimethyl sulfoxide or the mixture of 2,6dimethylphenol and chloroform (1:4 by weight), for dissolving the solid were used depending on the acid concentration. If the acid concentration in solid products was larger than $0.8 \mathrm{mmol} / \mathrm{g}$ of solid, $25 \mathrm{~mL}$ of DMSO was used as the solvent, in which $0.1-0.2 \mathrm{~g}$ of solid product was dissolved. If the acid concentration in the solid products was smaller than $0.8 \mathrm{mmol} / \mathrm{g}$ of solid, the sample solution was prepared from the refluxing of 1-2 g of solid product with $50 \mathrm{~g}$ of 2,6dimethylphenol/chloroform solvent at $130{ }^{\circ} \mathrm{C}$. Each resulted solution was titrated with $0.1 \mathrm{~N}$ potassium hydroxide/ethanol solution at room temperature. The potential of the solution versus the amount of the titrant added was recorded, and the plot was then used to determine the end point of titration. The experimental error of the titration was about $1 \%$. Moreover, the el emental composition of carbon and hydrogen in the solid products was measured by a Perkin-Elmer 2400 elemental analyzer.

The concentrations of the liquid products were analyzed by gas chromatrography. 1-Propanol was used as an internal standard. The mixed solution was injected into a gas chromatrograph and separated by a 2-m stainless steel column packed with DEGS 60/80 Chromosorb WAW DMCS. The components were carried by a nitrogen flow and detected by a flame ionization detector.

Calculation of Reaction Extent. The reaction extent of PET hydrolysis for kinetic study is defined as moles of carboxylic acid produced per gram of PET used, which was also the definition in the work of Campanelli et al. (1993). The acid concentration in the solid products can be measured from the experiments; therefore, the relation between the weight of PET used and the weight of solid products produced needs to be known to obtain the reaction extent. However, it was difficult to measure the accurate weight of the solid products after each reaction because of inevitable weight loss during the product treatments. In this research, the weight of solid products was solved from the mass balance equations derived from the following reactions
Table 1. Effect of Initial Charge Ratio on the Reaction Extent of PET Hydrolysisa

\begin{tabular}{cccc}
\hline $\begin{array}{c}\text { water:PET } \\
\text { weight ratio }\end{array}$ & $\begin{array}{c}\text { [COOH }^{\mathrm{b}} \\
(\mathrm{mmol} / \mathrm{g} \text { of PET) }\end{array}$ & $\begin{array}{c}\mathrm{EG} \\
\text { yieldc }(\%)\end{array}$ & $\begin{array}{c}\mathrm{DEG} \\
\text { yield }^{\mathrm{d}}(\%)\end{array}$ \\
\hline $10: 1^{\mathrm{e}}$ & 10.3 & 98.1 & 1.15 \\
$6: 1^{\mathrm{f}}$ & 10.0 & 92.5 & 2.47 \\
$2: 1^{\mathrm{g}}$ & 9.24 & 77.1 & 4.59
\end{tabular}

a Reaction temperature $=265^{\circ} \mathrm{C}$, time $=10 \mathrm{~min}, \mathrm{rpm}=400$ ${ }^{b}$ Reaction extent. c Moles of glycol-based unit produced divided by those in PET initially in the reactor. ${ }^{d}(D E G \times 2) /(D E G \times 2+$ EG) by molar basis. e Charge amount, water/PET $=100 \mathrm{~g} / 10 \mathrm{~g}$. ${ }^{f}$ Charge amount, water/PET $=90 \mathrm{~g} / 15 \mathrm{~g} .{ }^{\mathrm{g}}$ Charge amount, water/ $\mathrm{PET}=40 \mathrm{~g} / 20 \mathrm{~g}$.

occurring in the reactor.

$$
\begin{array}{r}
\sim \mathrm{C}_{6} \mathrm{H}_{4}-\mathrm{CO}-\mathrm{O}-\mathrm{C}_{2} \mathrm{H}_{4}-\mathrm{O} \sim+\mathrm{H}_{2} \mathrm{O} \leftrightarrow \\
\sim \mathrm{C}_{6} \mathrm{H}_{4}-\mathrm{COOH}+\mathrm{HO}-\mathrm{C}_{2} \mathrm{H}_{4}-\mathrm{O} \sim \\
2 \mathrm{HO}-\mathrm{C}_{2} \mathrm{H}_{4}-\mathrm{OH} \leftrightarrow \mathrm{HO}-\mathrm{C}_{2} \mathrm{H}_{4}-\mathrm{O}-\mathrm{C}_{2} \mathrm{H}_{4}-\mathrm{OH}+ \\
\mathrm{H}_{2} \mathrm{O}
\end{array}
$$

The first reaction represents the PET hydrolysis and the second one represents the side reaction. Campanelli et al. (1993) detected the oligomers and terephthalic acid in the aqueous phase but found that the concentrations of phthal ate groups in the liquid phase were negl igible. Therefore, the amount of solid products dissolved in the liquid phase was not accounted for doing mass balance in our study. The balance equations for overall and water masses in the reaction system can be written in the following form:

$$
\begin{aligned}
& \text { total balance: } \mathrm{W}+\mathrm{P}=\mathrm{X}+\mathrm{Y}+\mathrm{U}+\mathrm{V} \\
& \text { water balance: } \mathrm{W}=\mathrm{X}+18 \beta \mathrm{Y}-18 \mathrm{~V} / 106
\end{aligned}
$$

$W$ and $P$ represent the weights of water and PET used at the beginning of the reaction. $X, Y, U$, and $V$ are the weights of water, solid, ethylene glycol, and diethylene glycol in the reactor after the hydrolytic reactions. $\beta$ is the carboxylic acid concentration based on the weight of the solid product ( $\mathrm{mol} / \mathrm{g}$ of solid). The molecular weights of water and diethylene glycol are 18 and 106, respectively. With the known values of $\mathrm{W}, \mathrm{P}, \mathrm{U}, \mathrm{V}$, and $\beta$ measured from experiments, eqs 3 and 4 can be solved to obtain the values of $X$ and $Y$. The reaction extent, $\alpha$, can be calculated by the equation of $\alpha=\beta \mathrm{Y} / \mathrm{P}$.

\section{Results}

Hydrolytic Reactions of PET. The reaction extents, ethylene glycol (EG) yiel ds, and diethylene glycol (DEG) yields from PET hydrolysis at $265^{\circ} \mathrm{C}$ for $10 \mathrm{~min}$ with different charge ratios (water:PET) are listed in Table 1. The concentrations of carboxylic acid in each case was rather high. Especially, in the case of the largest charge of water, the carboxylic acid concentration was very close to the value of complete depolymerization, $10.4 \mathrm{mmol} / \mathrm{g}$ of PET. The liquid products were mostly ethylene glycol and a small amount of its dimer. The high yields of ethylene glycol which also corresponded to the high values of carboxylic acid concentration were obtained from all three cases. The production of diethylene glycol was observed in the case of low water charge. In summary, the reaction extents of PET hydrolysis slightly increased with the charge ratios of water to PET, and the production of diethylene glycol increased as the charge ratio decreased. 
Table 2. Elemental Analysis of Terephthalic Acid and Hydrolyzed Products

\begin{tabular}{lccc}
\hline & \multicolumn{3}{c}{ element } \\
\cline { 2 - 4 } & $\mathrm{C}(\%)$ & $\mathrm{H}(\%)$ & $\mathrm{O}(\%)^{\mathrm{a}}$ \\
\hline TPA (theoretical) & 57.84 & 3.64 & 38.52 \\
TPA & 57.52 & 3.64 & 38.84 \\
solid product $^{\mathrm{b}}$ & 57.31 & 3.72 & 38.97
\end{tabular}

a $\mathrm{O}(\%)=100-\mathrm{C}(\%)-\mathrm{H}(\%)$. b Solid products from PET hydrolysis while the charge ratio of water:PET $=10: 1$, reaction temperature $=265^{\circ} \mathrm{C}$, time $=10 \mathrm{~min}, \mathrm{rpm}=400$.

Table 3. Effect of Temperature on Reaction Extents of PET Hydrolysis ${ }^{a}$

\begin{tabular}{cccc}
\hline $\begin{array}{c}\text { temp. } \\
\left({ }^{\circ} \mathrm{C}\right)\end{array}$ & $\begin{array}{c}{[\mathrm{COOH}]^{\mathrm{b}}} \\
(\mathrm{mmol} / \mathrm{g} \text { of PET) }\end{array}$ & $\begin{array}{c}\mathrm{EG} \\
\text { yield }(\%)\end{array}$ & $\begin{array}{c}\mathrm{DEG} \\
\text { yield }(\%)\end{array}$ \\
\hline 235 & 2.15 & 5.24 & 0.00 \\
250 & 7.89 & 42.7 & 0.00 \\
265 & 10.0 & 92.5 & 2.47
\end{tabular}

a From a charge ratio of water:PET $=6: 1$ (charge amount, water $/$ PET $=90 \mathrm{~g} / 15 \mathrm{~g}$ ), reaction time $=10 \mathrm{~min}$ and $\mathrm{rpm}=400$. b Reaction extent.

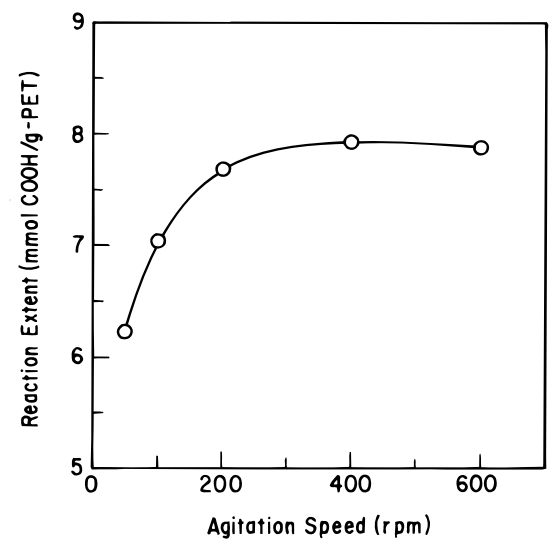

Figure 1. Effect of agitation speed on reaction extent of PET hydrolysis at $250{ }^{\circ} \mathrm{C}$ for $10 \mathrm{~min}$ while charge ratio (water:PET) = 6:1.

Table 2 lists the results of el emental analysis for the solid product from PET hydrolysis with a charge ratio (water:PET) of 10:1 as well as the standard sample terephthalic acid (TPA). Note, the experimental error of these measurements for hydrogen was $0.1 \%$ and for carbon was $0.2 \%$. Therefore, the elemental composition of the solid product listed in Table 2 was the same as that of terephthalic acid within the experimental error. The result confirms that the solid product at the nearly complete conversion of PET was terephthalic acid.

Table 3 compares the results of PET hydrolysis at three temperatures $\left(235,250\right.$, and $\left.265^{\circ} \mathrm{C}\right)$ for $10 \mathrm{~min}$, with a charge ratio (water:PET) of 6:1. The concentrations of carboxylic acid and the yields of ethylene glycol were found to increase with the increase of the reaction temperatures. Particularly, there was marked el evation of conversion between the temperatures of 235 and 250 ${ }^{\circ} \mathrm{C}$. The production of diethylene glycol was not observed at 235 and $250^{\circ} \mathrm{C}$ due to only a small amount of ethylene glycol produced.

Effect of Agitation Speed. To explore the influence of mass transfer inside the reactor, the effect of different agitation speeds $(50-600 \mathrm{rpm})$ on the apparent rate of PET hydrolysis at $250^{\circ} \mathrm{C}$ for $10 \mathrm{~min}$ was investigated. The charge ratio (water:PET) was 6:1. Figure 1 shows the plot of the reaction extent versus the agitation speed. It indicates that the reaction rate of PET

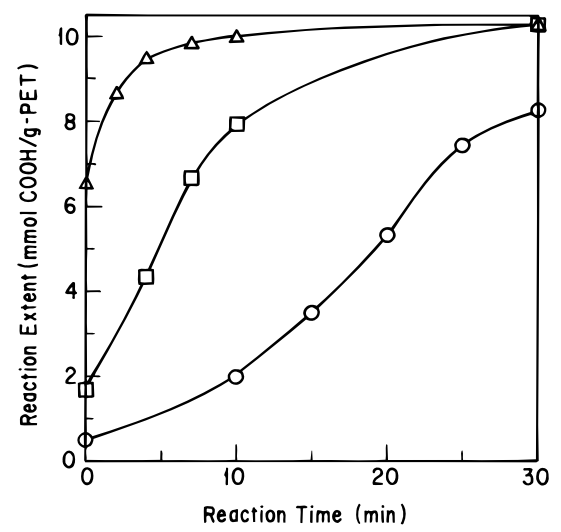

Figure 2. The reaction extent as a function of reaction time at (O) $235^{\circ} \mathrm{C},(\square) 250^{\circ} \mathrm{C}$, and $(\triangle) 265^{\circ} \mathrm{C}$, while the charge ratio of water:PET = 6:1.

hydrolysis increased with the agitation speed and approached a constant value when the agitation speed was larger than $400 \mathrm{rpm}$. The results suggest that no apparent resistance of mass transfer inside the reactor existed while high agitation speeds were applied. There fore, our later experiments for reacti on kinetics studies were carried out at the agitation speed of $400 \mathrm{rpm}$.

Reaction Kinetics. When the charge ratio (water: PET) was 6:1, the increases of carboxylic acid concentration as a function of reaction time at reaction temperatures ranging between 235 and $265{ }^{\circ} \mathrm{C}$ are depicted in Figure 2. Because reaction also occurred during temperatures increasing from room temperature to the designed "reaction temperatures", significant conversions of PET hydrolysis at the initial time were observed. The conversi ons achieved rather high values in a short time interval, less than $10 \mathrm{~min}$. The reaction rates of PET hydrolysis were fast at temperatures higher than $250^{\circ} \mathrm{C}$.

Kinetic Model. In the kinetic studies of PET hydrolysis by Golike and Lasoski (1960) and Campanelli et al. (1993), a second-order reaction model was used in the following form:

$$
\mathrm{d}[\mathrm{COOH}] / \mathrm{dt}=\mathrm{k}_{1}[\mathrm{EL}]\left[\mathrm{H}_{2} \mathrm{O}\right]
$$

where $[\mathrm{COOH}]$ represents the carboxylic acid concentration at time t. [EL] and $\left[\mathrm{H}_{2} \mathrm{O}\right]$ represent the concentrations of ester linkage and water. The rate constant of hydrolysis is $k_{1}$. In this model, only the forward reaction was considered, and it thus was merely applied in the kinetic analysis for the reaction at low hydrolytic conversions. In the present work, the conversions of PET hydrolysis, however, were rather high even in a short time interval. Therefore, the backward reaction as well as the forward reaction must be considered in the rate equation. The second-order model examined in this study is written in the following form:

$$
\mathrm{d}[\mathrm{COOH}] / \mathrm{dt}=\mathrm{k}_{1}\left\{[\mathrm{EL}]\left[\mathrm{H}_{2} \mathrm{O}\right]-[\mathrm{OH}][\mathrm{COOH}] / \mathrm{K}\right\}
$$

or

$$
\begin{array}{r}
\mathrm{d}[\mathrm{COOH}] / \mathrm{dt}=\mathrm{k}_{1}\left\{( [ \mathrm { EL } ] _ { \mathrm { i } } - [ \mathrm { COOH } ] ) \left(\left[\mathrm{H}_{2} \mathrm{O}\right]_{\mathrm{i}}-\right.\right. \\
\left.[\mathrm{COOH}])-[\mathrm{COOH}]^{2} / \mathrm{K}\right\}
\end{array}
$$

where $[\mathrm{OH}]$ is the hydroxyl concentration and $\mathrm{K}$ is the equilibrium constant of the reaction. $[E L]_{i}$ and $\left[\mathrm{H}_{2} \mathrm{O}\right]_{\mathrm{i}}$ represent the initial charge concentrations of ester linkage and water. Integrating eq 7 gives the following 
Table 4. Equilibrium Constants of PET Hydrolysis at Different Reaction Temperatures

\begin{tabular}{cc}
\hline temp. $\left({ }^{\circ} \mathrm{C}\right)$ & equilibrium constant, ${ }^{a} \mathrm{~K}$ \\
\hline 235 & 7.09 \\
250 & 3.99 \\
265 & 1.53 \\
a From a charge ratio of water:PET $=2: 1$.
\end{tabular}

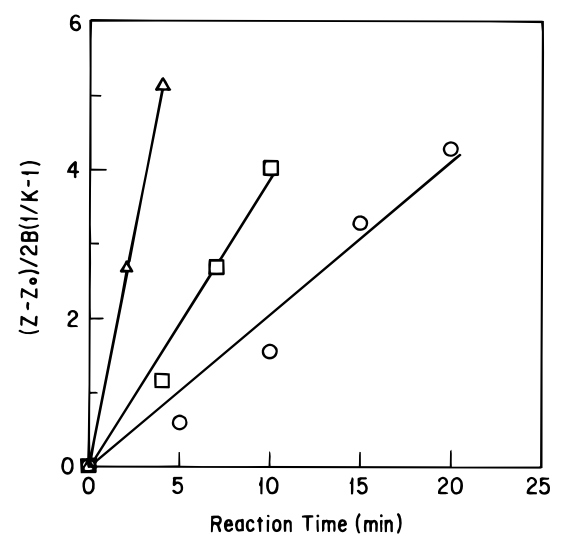

Figure 3. Kinetic plots by a second-order model for reactions at (O) $235^{\circ} \mathrm{C}$, ( $\left.\square\right) 250^{\circ} \mathrm{C}$, and $(\triangle) 265^{\circ} \mathrm{C}$.

equation:

$$
\left(\mathrm{Z}-\mathrm{Z}_{0}\right) / 2 \mathrm{~B}(1-\mathrm{K})=\mathrm{k}_{1} \mathrm{t}
$$

where $\mathrm{Z}=\ln |[\mathrm{COOH}]+\mathrm{A}-\mathrm{B}| /[\mathrm{[COOH}]+\mathrm{A}+\mathrm{B} \mid, \mathrm{Z}=$ $\mathrm{Z}_{0}$ at $\mathrm{t}=0, \mathrm{~A}=-\left([\mathrm{EL}]_{\mathrm{i}}+\left[\mathrm{H}_{2} \mathrm{O}\right]_{\mathrm{i}}\right) / 2(1-\mathrm{I} / \mathrm{K})$, and $\mathrm{B}=$ $\left\{A^{2}-[E L]_{i}\left[H_{2} O\right]_{i} /(1-1 / K)\right\}^{1 / 2}$. It is noted that $A$ and $\mathrm{B}$ are constants for specific reaction conditions. The rate constant of hydrolysis would thus be estimated by fitting experimental data to eq 8 , after the equilibrium constant was obtained. The equlibrium constant for PET hydrolysis, K, can be written as

$$
\mathrm{K}=[\mathrm{COOH}]_{e}[\mathrm{OH}]_{e} /[\mathrm{EL}]_{e}\left[\mathrm{H}_{2} \mathrm{O}\right]_{e}
$$

where the subscript e represents the concentrations of products or reactants at an equilibrium state. To estimate the equilibrium constant, the hydrolytic reactions were run for a long period of time to reach an equilibrium state. Because the initial concentrations of reactants were known, the equlibrium constants for PET hydrolysis would thus be estimated after obtaining the product concentrations. The values of equilibrium constants for different temperatures calculated by eq 9 were listed in Table 4.

Figure 3 is the plot of $\left(Z-Z_{0}\right) / 2 B(1-K)$ in eq 8 versus time at three different reaction temperatures. In the figure, the data from the temperatures at 235 and $250{ }^{\circ} \mathrm{C}$ actually show upward curves instead of straight lines passing through the origin. These results indicate that the second-order model cannot describe the reaction kinetics well. The upward curves suggest that the reaction rate of PET hydrolysis increased with the reaction time or the product concentrations. Moreover, if the progress of PET hydrolysis obeyed a second-order model, the reaction rate would monotonically decrease as time increased. Nevertheless, the slope in Figure 2 (the reaction rate) has a maximum value for the case of $235{ }^{\circ} \mathrm{C}$. It means that the reaction rate of PET hydrolysis was accelerated by increasing concentrations of the products. Therefore, it may be reasonably proposed that the hydrolysis reaction of PET possesses

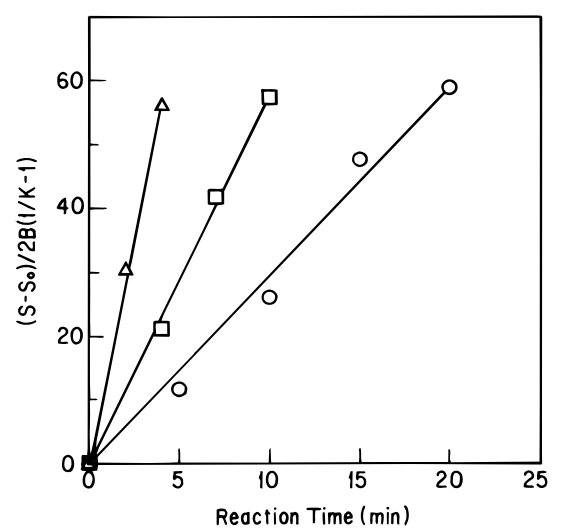

Figure 4. Kinetic plots by a second-order model with autocatalytic reaction for the $\mathrm{PET}$ hydrolysis at $(\mathrm{O}) 235^{\circ} \mathrm{C}$, (口) $250^{\circ} \mathrm{C}$, and $(\triangle)$ $265^{\circ} \mathrm{C}$.

an autocatalytic mechanism induced by the carboxyl group. As shown below, we proposed two autocatalytic models (first or half an order with respect to the carboxyl concentration) to analyze the kinetics of PET hydrolysis:

$$
\mathrm{d}[\mathrm{COOH}] / \mathrm{dt}=\mathrm{k}_{2}\left\{[\mathrm{EL}]\left[\mathrm{H}_{2} \mathrm{O}\right][\mathrm{COOH}]-[\mathrm{COOH}]^{3} / \mathrm{K}\right\}
$$

$$
\begin{array}{r}
\mathrm{d}[\mathrm{COOH}] / \mathrm{dt}=\mathrm{k}_{3}\left\{[\mathrm{EL}]\left[\mathrm{H}_{2} \mathrm{O}\right][\mathrm{COOH}]^{1 / 2}-\right. \\
\left.[\mathrm{COOH}]^{5 / 2} / \mathrm{K}\right\}
\end{array}
$$

where $k_{2}$ and $k_{3}$ represent the rate constants of hydrolysis in the autocatalytic models. The integration of eq 10 gives the following relationship:

$$
\left(Q-Q_{0}\right) / 2\left(A^{2}-B^{2}\right)(1-1 / K)=k_{2} t
$$

where $\mathrm{Q}=\ln [\mathrm{COOH}]^{2} /\left(\{[\mathrm{COOH}]+\mathrm{A}\}^{2}-\mathrm{B}^{2}\right)-(\mathrm{A} / \mathrm{B})$ $\ln |[\mathrm{COOH}]+\mathrm{A}-\mathrm{B}| /[\mathrm{COOH}]+\mathrm{A}+\mathrm{B} \mid$, and $\mathrm{Q}=\mathrm{Q}_{0}$ at $t=0$. The integration of eq 11 gives the following equation:

$$
\left(\mathrm{S}-\mathrm{S}_{0}\right) / 2 \mathrm{~B}(1-\mathrm{K})=\mathrm{k}_{3} \mathrm{t}
$$

where if $\mathrm{K}$ is larger than $1, \mathrm{~S}=(-\mathrm{A}+\mathrm{B})^{-1 / 2} \operatorname{|n} \mid[\mathrm{COOH}]^{1 / 2}$ $-(A+B)^{1 / 2}\left|/[\mathrm{COOH}]^{1 / 2}+(-A+B)^{1 / 2}\right|-\ln \mid[\mathrm{COOH}]^{1 / 2}$ $-(-A-B)^{1 / 2} / /[C O O H]^{1 / 2}+(-A-B)^{1 / 2} \mid$, and if $K$ is smaller than $1, \mathrm{~S}=(-\mathrm{A}+\mathrm{B})^{-1 / 2} \ln \mid[\mathrm{COOH}]^{1 / 2}-(\mathrm{A}+$ B $)^{1 / 2} / /[\mathrm{COOH}]^{1 / 2}+(-\mathrm{A}+\mathrm{B})^{1 / 2} \mid-\tan ^{-1}[\mathrm{COOH}]^{1 / 2} /(\mathrm{A}+$ $B)^{1 / 2}, \mathrm{~S}=\mathrm{S}_{0}$ at $\mathrm{t}=0$.

Using linear regression (GLM program of SAS), we calculated that the R-square, indicating the linearity of fitting to the tested model, was 0.996 for eq 12 and was 0.999 for eq 13 , in contrast to being only 0.985 for eq 8. Both autocatalytic models fit the experimental data better than the second-order model; however, eq $13 \mathrm{fit}$ the best. Therefore, the autocatalytic model with $1 / 2$ order to the carboxylic acid concentration was chosen for the description of reaction kinetics. $\left(\mathrm{S}-\mathrm{S}_{0}\right) / 2 \mathrm{~B}(1$ $-K$ ) in eq 13 versus time was plotted in Figure 4. The fitting of kinetic data gave nearly three straight lines through the origin for the three reaction temperatures. The rate constants were calculated from the slopes of the lines and are shown in Table 5. It is noted that the values of rate constants in Table 5 were functions of initial charge ratio at the same reaction temperature, which were not expected for the rate law of reaction kinetics. Therefore, the kinetic data of concentrations 
Table 5. Reaction Rate Constants (Based on the Weight of PET) of PET Hydrolysis with Different Charge Ratios at Different Temperatures

\begin{tabular}{cccc}
\hline \multirow{2}{*}{$\begin{array}{c}\text { charge ratio } \\
\text { water:PETa }\end{array}$} & \multicolumn{3}{c}{ rate constant $\left((\mathrm{g} \text { of PET/mol })^{3 / 2} / \mathrm{min}\right)$} \\
\cline { 2 - 4 } $235{ }^{\circ} \mathrm{C}$ & $250{ }^{\circ} \mathrm{C}$ & $265^{\circ} \mathrm{C}$ \\
\hline $2: 1$ & 10.2 & 5.77 & 14.4 \\
$6: 1$ & 2.95 & 3.12 & \\
$10: 1$ & 0.892 & \multicolumn{3}{c}{}
\end{tabular}

Table 6. Reaction Volumes for the PET Hydrolysis with Different Charge Ratios at Different Temperatures

\begin{tabular}{cccc}
\hline \multirow{2}{*}{ charge ratio } & \multicolumn{3}{c}{ reaction volume $(\mathrm{mL} / \mathrm{g}$ of PET) } \\
\cline { 2 - 4 } water:PETa & $235^{\circ} \mathrm{C}$ & $250{ }^{\circ} \mathrm{C}$ & $265^{\circ} \mathrm{C}$ \\
\hline $2: 1$ & 3.00 & 2.99 & 2.93 \\
$6: 1$ & 7.88 & 8.00 & 8.13 \\
$10: 1$ & 12.6 & 12.9 & 13.1 \\
\multicolumn{2}{c}{ a Charge amounts } & were the same as those in Table 1.
\end{tabular}

Table 7. Reaction Rate Constants (Based on the Reaction Volume) of PET Hydrolysis with Different Charge Ratios at Different Temperatures

\begin{tabular}{cccc}
\hline \multirow{2}{*}{$\begin{array}{c}\text { charge ratio } \\
\text { water:PET }\end{array}$} & \multicolumn{3}{c}{ rate constant $\left(10^{-5}(\mathrm{~L} / \mathrm{mol})^{3 / 2} / \mathrm{s}\right)$} \\
\cline { 2 - 4 } $235^{\circ} \mathrm{C}$ & $250{ }^{\circ} \mathrm{C}$ & $265^{\circ} \mathrm{C}$ \\
\hline $2: 1$ & 2.80 & & \\
$6: 1$ & 3.44 & 6.88 & 17.6 \\
$10: 1$ & 2.67 & 7.59 & \\
a Charge amounts & were the same as those in Table 1.
\end{tabular}

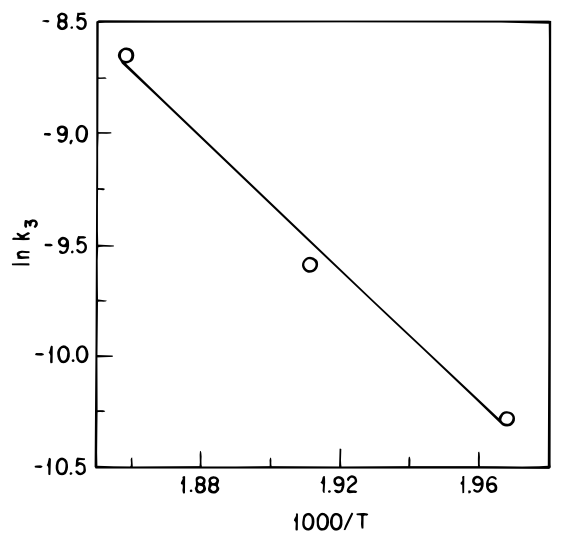

Figure 5. Arrhenius plot for the hydrolysis of PET.

based on the weight of PET, following the work of Campanelli et al. (1993), may not be right. The rate constants should be transformed into the values based on volume. However, the reaction volume for PET hydrolysis depends on the reaction temperature and charge ratio. We assumed that an ideal solution, a constant reaction volume, and water at vapor-liquid equilibrium were in the reaction system. In Table 6, the estimated reaction volumes per gram of PET as functions of charge ratios and reaction temperatures are listed. From the transformation, the rate constants of PET hydrolysis based on the reaction volume were calculated and summarized in Table 7. It shows that the rate constants of PET hydrolysis were much closer for different initial concentrations of reactants. From the rate constant versus temperature data of the charge ratio (water:PET) 6:1, the Arrhenius plot is depicted in Figure 5. The activation energy for PET hydrolysis calculated from the slope of this plot was $123 \mathrm{~kJ} / \mathrm{mol}$.

\section{Discussion}

The flow patterns of fluid in an agitated vessel are complex; however, the mixing efficiency can be simply correlated with Reynol ds numbers (McCabe et al., 1985). For the fluid in an agitated vessel, Reynol ds number is defined as $\mathrm{Re}=\mathrm{D}^{2} \mathrm{~N} \rho / \mu$, where $\mathrm{D}$ and $\mathrm{N}$ represent the diameter and peripheral speed of the impeller and $\rho$ and $\mu$ represent the density and viscosity of the fluid. Using the correlation of viscosities with reduced temperatures and pressures (Bird et al., 1960), we estimated that the viscosity of water is about $0.46 \mathrm{cp}$ at $250{ }^{\circ} \mathrm{C}$ with the saturated pressure. Reynolds numbers in the reactor at $250^{\circ} \mathrm{C}$ were calculated to be 22000 with the agitation speed of $400 \mathrm{rpm}$ and 2800 with the agitation speed of $50 \mathrm{rpm}$ when the fluid was assumed to be composed of pure water. However, the values of Reynolds number for the reaction system should be much lower than those estimated because the real solution included viscous PET melts. It means that the fluid in the reactor with low agitation speeds $(<100 \mathrm{rpm})$ would not reach a turbulent state because of low Reynolds numbers. In other words, well-mixing would not be expected for the reactants and products when the agitation speed was low. It is consistent with that the hydrolysis rate increased with the agitation speed when the agitation speed was bel ow $100 \mathrm{rpm}$ (F igure 1), indicating that the hydrolytic reaction with slow stirring was partly controlled by mass transfer. When the agitation speed was higher than about $200 \mathrm{rpm}$, the reaction rate was shown to be independent of agitation speed. It indicates that the mixing efficiency was enhanced with fast stirring and the hydrolytic reaction was not limited by the mass transfer.

From the results in Table 4, the equilibrium constant decreased with the reaction temperature, indicating that the hydrolytic depolymerization of PET melts is exothermic. The heat release per ester linkage hydrolyzed was calculated to be $115 \mathrm{~kJ}$ by the van't H off equation (Sandler, 1989). If there existed apparent resistance of heat transfer inside the reactor at low agitation speeds, the conversion of PET hydrolysis would have increased due to the thermal effect. It was shown in Figure 1 that the reaction extent at low agitation speed was lower than that at high agitation speed. Therefore, it suggests that the resistance of heat transfer in the reactor might be much smaller than that of mass transfer.

In the examination of the above-mentioned kinetic models, the side reaction, the dimerization of ethylene glycol, was ignored. At the reaction conditions of high water concentration, the conversion of the side reaction was less than 3\%. Therefore, the error for kinetic analysis due to the neglect of the side reaction would not be significant. In addition, the error for the estimation of reactants and products concentrations in the liquid phase was inevitable. It thus caused the slight difference of the calculated rate constants for PET hydrolysis from different charge ratios (Table 7).

In this study, the hydrolytic reaction of PET was found to possess a kinetic model of autocatalysis by the carboxyl group. In the early studies (Ravens and Ward, 1961; Zimmerman and Kim, 1980), similar kinetic phenomena were also observed for PET hydrolysis with low conversions at temperatures bel ow the melting point of PET. The rate expression in eq 11 or 13 was an autocatalytic model with $1 / 2$ order in carboxylic acid 
Table 8. Reaction Extents of Hydrolysis for Different PET Resins ${ }^{\mathrm{a}}$

\begin{tabular}{lcccc}
\hline \multicolumn{1}{c}{ PET } & $\begin{array}{c}\text { IV } \\
\text { (dL/g) }\end{array}$ & $\begin{array}{c}\text { average } \\
\text { molecular } \\
\text { weight }^{\mathrm{b}}\end{array}$ & $\begin{array}{c}\text { [COOH] } \\
\text { (mmol/g } \\
\text { of PET) }\end{array}$ & $\begin{array}{c}\mathrm{EG} \\
\text { yield } \\
(\%)\end{array}$ \\
\hline $\begin{array}{l}\text { fresh chips } \\
\text { recycled flakes } \\
\text { (transparent) }\end{array}$ & 0.54 & 15000 & 7.89 & 42.7 \\
$\begin{array}{c}\text { recycled flakes } \\
\text { (green) }\end{array}$ & 0.80 & 26000 & 7.90 & 47.1 \\
& & 22000 & 7.41 & 39.6
\end{tabular}

a From charge ratio water:PET $=6: 1$, reaction temperature $=$ $250{ }^{\circ} \mathrm{C}$, reaction time $=10 \mathrm{~min}$. ${ }^{\mathrm{b}}$ Calculated on the basis of the relation presented in Kamatani et al. (1980). ' Reaction extent.

concentration. It suggests that the hydrolytic depolymerization of PET may be catalyzed by the hydrogen ion formed by the diassociation of the carboxylic acid because the carboxyl group of hydrolyzed products, such as terephthalic acid $\left(\mathrm{pK}_{1}=3.51\right.$ and $\mathrm{pK}_{2}=4.82$ ), can be dissociated to a hydrogen ion in water. The dissociation can be expressed as follows:

$$
\sim \mathrm{C}_{6} \mathrm{H}_{4}-\mathrm{COOH} \leftrightarrow \sim \mathrm{C}_{6} \mathrm{H}_{4}-\mathrm{COO}^{-}+\mathrm{H}^{+}
$$

The concentration of the hydrogen ion is proportional to the square root of the carboxylic acid concentration. It is in good agreement with the characteristics of the autocatalytic model by the carboxyl group. Therefore, it is reasonable to propose that PET hydrolysis follows a typical mechanism of nucleophilic addition-elimination induced by the hydrogen ion as shown by the following steps:

$$
\begin{aligned}
& \sim \mathrm{C}_{6} \mathrm{H}_{4}-\mathrm{CO}-\mathrm{O}-\mathrm{C}_{2} \mathrm{H}_{4}-\mathrm{O} \sim+\mathrm{H}^{+} \leftrightarrow \\
& \sim \mathrm{C}_{6} \mathrm{H}_{4}-\mathrm{C}\left(\mathrm{OH}^{+}\right)-\mathrm{O}-\mathrm{C}_{2} \mathrm{H}_{4}-\mathrm{O} \sim \\
& \sim \mathrm{C}_{6} \mathrm{H}_{4}-\mathrm{C}\left(\mathrm{OH}^{+}\right)-\mathrm{O}-\mathrm{C}_{2} \mathrm{H}_{4}-\mathrm{O} \sim+\mathrm{H}_{2} \mathrm{O} \leftrightarrow \\
& \sim \mathrm{C}_{6} \mathrm{H}_{4}-\mathrm{C}(\mathrm{OH})_{2}-\left(\mathrm{OH}^{+}\right)-\mathrm{C}_{2} \mathrm{H}_{4}-\mathrm{O} \sim \\
& \sim \mathrm{C}_{6} \mathrm{H}_{4}-\mathrm{C}(\mathrm{OH})_{2}-\left(\mathrm{OH}^{+}\right)-\mathrm{C}_{2} \mathrm{H}_{4}-\mathrm{O} \sim \leftrightarrow \\
& \sim \mathrm{C}_{6} \mathrm{H}_{4}-\mathrm{C}\left(\mathrm{OH}^{+}\right)-\mathrm{OH}+\mathrm{HO}-\mathrm{C}_{2} \mathrm{H}_{4}-\mathrm{O} \sim \\
& \sim \mathrm{C}_{6} \mathrm{H}_{4}-\mathrm{C}\left(\mathrm{OH}^{+}\right)-\mathrm{OH} \leftrightarrow \sim \mathrm{C}_{6} \mathrm{H}_{4}-\mathrm{COOH}+\mathrm{H}^{+}
\end{aligned}
$$

The conversions of PET hydrolysis in our study were found to be higher than those in the work by Campanelli et al. (1993) with similar reaction conditions. At the same reaction conditions of $250^{\circ} \mathrm{C}$ and $5 \mathrm{mmol} / \mathrm{g}$ of PET of the carboxyl concentration, the hydrolysis rate observed in this study was 1.7 times higher than that in Campanelli's study. It should be noted that there were some different reaction conditions in these two investigations. For example, PET and water used in the hydrolytic reaction were different between the two studies. In their study, the PET resins of IV with 0.80 and the water of HPLC grade were used as the reactants. To compare with their study, we have also investigated the resins from the recycled bottle flakes, whose intrinsic viscosities were 0.80 (transparent flakes) and 0.70 (green flakes), respectively, as reactants of PET hydrolysis. The reaction extents of hydrolysis at 250 ${ }^{\circ} \mathrm{C}$ for $10 \mathrm{~min}$ were summarized in Table 8 . The carboxylic acid concentration and the yield of ethylene glycol over the resins with the highest IV value was found close to those of the resin with the lowest IV value. This suggests that the shape and the molecular weight of PET resin should not influence the hydrolytic reaction in its melting state at high temperatures. However, the hydrolytic conversion of the green flakes was lower than those of the other resins. It may be due to the inhibition by some additives introduced during the processing of green PET bottles. Moreover, we have also compared the conversions for PET hydrolysis using deionized water and HPLC-grade water as reactants. The hydrolytic conversions for these two cases were found to be similar, even though the $\mathrm{pH}$ values of the two kinds of water were different. Therefore, the effect of the reactants on the discrepancy of reaction efficiency between these two studies can be excluded.

The main difference between these two studies might be the reactor size and stirring efficiency. In the study by Campanelli et al. (1993), a 2-L reactor was used, but the effect of the mixing conditions in the vessel was not well-investigated. In contrast, a reactor of small volume $(300 \mathrm{~mL}$ ) was used in this study, and proper mixing of products and reactants was provided by conducting the agitation at high speed. Ther efore, it is conceivable that the discrepancy on the reaction rates of PET hydrolysis was caused by the different mixing efficiency. In other words, poor mixing could occur in their experiments as suggested in the Introduction section. This would make the hydrolysis rate controlled by the mass-transfer step and lower the observed reaction rate. Furthermore, the activation energy found by Campanelli et al. (1993) was much lower than those obtained in early findings (Golike and Lasoski, 1960; Ravens and Ward, 1961) and this work. The result further suggests the existence of mass-transfer limitations in their observations.

\section{Conclusions}

The hydrolytic depolymerization of PET melts was investigated in a pressurized reactor. Terephthalic acid and ethylene glycol were recovered from the hydrolyzed products. High hydrolytic conversion of PET was obtained by increasing the reaction temperature or charge concentration of water. The powerful agitation provided proper mixing so that no significant limitation of mass transfer was found in the reactor system. The kinetic models considering both forward and backward reactions were proposed. An autocatalytic model with a $1 / 2$ order of carboxylic acid concentration was found to best describe the kinetic characteristic of PET hydrolysis. This suggests a mechanism that the hydrolytic depolymerization of PET might be catalyzed by the hydrogen ion dissociated from the carboxyl group. The activation energy for the PET hydrolysis, as estimated from the Arrhenius plot, was $123 \mathrm{~kJ} / \mathrm{mol}$.

\section{Acknowledgment}

The financial support for this study from the National Science Council of Tai wan, Republic of China, through Grant No. NSC-85-2214-E-182-001 is gratefully acknowl edged.

\section{Nomenclature}

$A=$ constant, defined in eq 8

$\mathrm{B}=$ constant, defined in eq 8

$[\mathrm{COOH}]=$ concentration of carboxyl group, $\mathrm{mmol} / \mathrm{g}$ of PET

$[E L]=$ concentration of ester linkage, $\mathrm{mmol} / \mathrm{g}$ of $\mathrm{PET}$

$\left[\mathrm{H}_{2} \mathrm{O}\right]=$ concentration of water, $\mathrm{mmol} / \mathrm{g}$ of PET

$\mathrm{k}=$ rate constant

$\mathrm{K}=$ equilibrium constant 
$[\mathrm{OH}]=$ concentration of hydroxyl group, $\mathrm{mmol} / \mathrm{g}$ of PET

$\mathrm{P}=$ charge weight of $\mathrm{PET}$

$\mathrm{Q}=$ reaction extent, defined in eq 12

$\mathrm{S}=$ reaction extent, defined in eq 13

$\mathrm{t}=$ reaction time

$U=$ weight of ethylene glycol after the reaction

$\mathrm{V}=$ weight of diethylene glycol after the reaction

$\mathrm{W}=$ charge weight of water

$X=$ weight of water after the reaction

$Y=$ weight of solid product after the reaction

$Z=$ reaction extent, defined in eq 8

\section{Greek Letters}

$\alpha=$ carboxyl concentration based on the weight of polymer, $\mathrm{mol} / \mathrm{g}$ of PET

$\beta=$ carboxyl concentration based on the weight of solid product, $\mathrm{mol} / \mathrm{g}$ of solid

\section{Subscripts}

$\mathrm{i}=$ at initial charge

$0=$ at reaction time zero

$\mathrm{e}=$ at equilibrium

\section{Literature Cited}

Ballara, A.; Verdu, J. Physical Aspects of the Hydrolysis of Polyethylene Terephthalate. J . Polym. Degrad. Stab. 1989, 26, 361.

Bird, R. B.; Stewart, W. E.; Lightfoot, E. N. Transport Phenomena; J ohn Wiley \& Sons: New York, 1960; pp 8-16.

Campanelli, J . R.; Kamal, M. R.; Cooper, D. G. A Kinetic Study of the Hydrolytic Degradation of Polyethylene Terephthalate at High Temperatures. J . Appl. Polym. Sci. 1993, 48, 443.

Campanelli, J . R.; Cooper, D. G.; Kamal, M. R. Catalyzed Hydrolysis of Polyethylene Terephthalate Melts. J . Appl. Polym. Sci. 1994, 53, 985.
Culp, E. Conference Charts a Global Future for Recycling Efforts. Mod. Plast. Int. 1994, May, 24.

Golike, R. C.; Lasoski, S. W. Kinetics of Hydrolysis of Polyethylene Terephthalate Films. J. Phys. Chem. 1960, 64, 895.

Kamatani, H.; Konagaya, S.; Nakamura, S. Effect of Phosphoric Acid on the Polycondensation of Bis(2-Hydroxyethyl) Terephthalate Catalyzed by Sb(III) Compounds. Polym. J . 1980, 12, 125.

Launay, A.; Thominette, F.; Verdu, J . Hydrolysis of Poly(Ethylene Terephthalate): a Kinetic Study. J . Polym. Degrad. Stab. 1994, 46, 319.

Mandoki, J . W. Depolymerization of Condensation Polymers. U.S. Patent 4065 762, 1986.

McCabe, W. L.; Smith, J . C.; Harriott, P. Unit Operations of Chemical Engineering, 4th ed.; McGraw-Hill: New York, 1985; pp 229-232.

Nir, M. M.; Miltz, J .; Ram, A. Update on Plastics and the Environment. Progress. Plast. Eng. 1993, 49, 75.

Paszun, D.; Spychaj, T. Chemical Recycling of Poly(ethylene terephthalate). Ind. Eng. Chem. Res. 1997, 36, 1373.

Ravens, D. A. S.; Ward, I. M. Chemical Reactivity of Polyethylene Terephthalate. Trans. Faraday Soc. 1961, 57, 150.

Rosen, B. I. Preparation of Purified Terephthalic Acid from Waste Polyethylene Terphthalate. U.S. Patent 5095 145, 1992.

Sandler, S. I. Chemical and Engineering Thermodynamics, 2nd ed.; J ohn Wiley \& Sons: New York, 1989; pp 505-508.

Sao, K. S.; Cloyd, J. D. Kinetics of Hydrolysis and Thermal Degradation of Polyester Melts. J . Appl. Polym. Sci. 1991, 42, 845.

West, S. M. I mproved Polyethylene Terphthalate Decontamination. PCT Int. Appl. WO 95/27753, 1995.

Zimmerman, H.; Kim, N. T. Investigations on Thermal and Hydrolytic Degradation of Poly(Ethylene Terephthalate). Polym. Eng. Sci. 1980, 20, 680.

Received for review August 4, 1997 Revised manuscript received J anuary 5, 1998 Accepted J anuary 11, 1998

IE970543Q 